\title{
Short-term storage of the oocytes affects the ploidy status in the yellowtail tetra Astyanax altiparanae
}

\author{
Matheus Pereira dos Santos ${ }^{1}$, Nivaldo Ferreira do Nascimento ${ }^{2}$, George Shigueki Yasui ${ }^{3}$, \\ Nycolas Levy Pereira ${ }^{2}$, Takafumi Fujimoto ${ }^{4}$, José Augusto Senhorini ${ }^{3}$ \\ and Laura Satiko Okada Nakaghi ${ }^{2}$ \\ Aquaculture Center, São Paulo State University, Jaboticabal, Brazil; National Center for Research and Conservation of \\ Continental Fish, Chico Mendes Institute of Biodiversity Conservation, Pirassununga, Brazil; and Faculty of Fisheries \\ Sciences, Hokkaido University, Hakodate, Japan
}

Date submitted: 16.08.2017. Date revised: 14.11.2017. Date accepted: 07.12.2017

\section{Summary}

In fish, many factors can affect reproduction during in vitro fertilization, therefore determination of the factors that affect affecting gamete quality is needed. However, few studies have focused on gamete quality and the ploidy status. This study was conducted to elucidate whether oocyte storage can affect ploidy status, survival, and embryo viability in the characid species Astyanax altiparanae. Oocytes were stored in Dulbecco's phosphate-buffered saline (PBS) at $26^{\circ} \mathrm{C}$, then aliquots were fertilized immediately after extrusion (control) and also after 60, 120, 180, and 240 min of storage. Fertilization and hatching rates were measured, and the developmental stages were analyzed at each stage before describing the main abnormalities. Ploidy status was analyzed by flow cytometry and blood smear. In the control group, $100 \%$ of the samples were diploid. After treatment for $60 \mathrm{~min}, 95.56 \pm 4.44 \%$ samples were diploid and $4.44 \pm 4.44 \%$ were triploid. After $120 \mathrm{~min}, 94.44 \pm 9.62 \%$ of the samples was diploid and $5.56 \pm 5.56 \%$ were triploid; $100 \%$ of the samples were diploid after $180 \mathrm{~min}$ and, after $240 \mathrm{~min}$, there was no survival. In other treatments, the highest percentage of hatching was after $60 \mathrm{~min}(88.93 \pm 5.15 \% ; P=0.015)$, and treatment with $180 \mathrm{~min}$ storage resulted in the highest percentage of abnormal larvae $(95.76 \pm 12.67 \%$; $P=0.012$ ). These results show that oocyte storage can affect ploidy status and may be an interesting parameter for analysis in studies on chromosome set manipulation and micromanipulation.

Keywords: Embryogenesis, Gametes, Morphology, Polyploidy, Reproduction

\section{Introduction}

Biotechnology applied to reproduction is a fundamental tool for the improvement of aquaculture production and preservation studies of fish species. Chimerism and transgenics in Misgurnus anguillicaudatus (Tanaka et al., 2009; Yasui et al., 2014), androgenesis in

\footnotetext{
${ }^{1}$ All correspondence to: Aquaculture Center, São Paulo State University, Jaboticabal, Brazil E-mail: matheusps.pereira@ gmail.com

${ }^{2}$ Aquaculture Center, São Paulo State University, Jaboticabal, Brazil.

${ }^{3}$ National Center for Research and Conservation of Continental Fish, Chico Mendes Institute of Biodiversity Conservation, Pirassununga, Brazil.

${ }^{4}$ Faculty of Fisheries Sciences, Hokkaido University, Hakodate, Japan.
}

Oreochromis niloticus, gynogenesis in Misgurnus mizolepis (Komen \& Thorgaard, 2007), and intracytoplasmic sperm injection in Oryzias latipes (Otani et al., 2009) are examples of successful consolidation techniques, presenting the potential for large-scale application.

These studies are based on parameters related to fertilization, embryonic development, and hatching rate abnormality indicators that are critical in determining the feasibility of chosen protocols. However, the specific causes of the abnormalities during experiments are not elucidated. The reproductive management and extraction of gametes under laboratory conditions can directly influence the final outcome of these techniques, including chromosomal manipulation tests and embryogenesis. These factors directly depend on the viability and survival of embryos and, consequently, the quality of manipulated gametes and optimization of its fertilization (Sun et al., 2005; Piferrer et al., 2009). 
Among causes of these abnormalities, the ploidy of these animals may be noted and may be altered during implementation of the techniques. Polyploidy in fish is expressed spontaneously and can be due to various causes. Some studies have reported the recurrence of spontaneous triploids. (Morelli et al., 1983; Maistro et al., 1994; Machado et al., 2012). The occurrence of these spontaneous variations may compromise the accuracy of the results in chromosome manipulation studies and micromanipulation.

Given the above constraints, this study was conducted to elucidate if storage in the short term is one of the factors capable of affecting the ploidy of neotropical characid $A$. altiparanae, an interesting model for studies in applied biotechnology and chromosomal manipulation. This species is of particular interest as its reproductive biology, one of the most basic requirements for applied studies, is already well described in the indexed literature (Pereira-Santos et al., 2016). Moreover, other basic information on triploidy (Adamov et al., 2016), growth and reproduction (Nascimento et al., 2017), induction techniques of triploid individuals, and aspects related to their growth and nutrition under laboratory conditions (Bertolini et al., 2017) are already well established for the species, forming a technological package for the application of biotechnology studies in neotropical native species.

\section{Materials and methods}

All procedures were performed according to the Ethics Committee for the use of Animals of the National Research and Biodiversity Conservation Continental Aquatic Center (CEUA/CEPTA \#02031.000033/ 2015-11).

\section{Induction of reproduction and fertilization}

Adult specimens of $A$. altiparanae were used in the experiments. To establish a broodstock, fish were collected in the Mogi Guaçu River $\left(21.925706^{\circ} \mathrm{S}\right.$, $47,369496^{\circ} \mathrm{W}$ ) and kept in $1000 \mathrm{~m}^{2}$ earthen tanks at the National Center for Research and Conservation of Aquatic Biodiversity Continental/Chico Mendes Institute for Biodiversity Conservation (CEPTA/ICMBio) in Pirassununga, Brazil. The fish were fed twice a day with a commercial pellet (1 $\mathrm{mm}$ diameter, $45 \%$ $\left.\mathrm{CP}, 4.200 \mathrm{kcal} \mathrm{kg}^{-1}\right)$. For in vitro fertilization, the procedures for induced maturation and fertilization were used from the laboratory's previous protocol (Yasui et al., 2014). Males $(\sim 6 \mathrm{~cm})$ and females $(\sim 9$ $\mathrm{cm})$ were anaesthetised using menthol $\left(100 \mathrm{mg} \mathrm{l}^{-1}\right)$ and injected with OVOPEL $®$ [(D-Ala6, Pro9-Net) - mGnRH + metoclopramide] ( $3 \mathrm{mg} \mathrm{kg}^{-1}$ for males and females). After injection, the fish were kept in a 400-litre aquarium with the temperature set at $26^{\circ} \mathrm{C}$. At the start of spawning behaviour (males following the females through the aquarium), fish were collected and anaesthetised as indicated above. Sperm were collected using a micropipette $1000 \mu \mathrm{l}$ (Eppendorf, Germany) and immediately transferred to a $1.5 \mathrm{ml}$ tube containing $400 \mu \mathrm{l}$ of modified Ringer's solution $\left(\mathrm{NaCl} 128.3 \mathrm{mM}, \mathrm{KCl} 23.6 \mathrm{mM}, \mathrm{CaCl}_{2} 3.6 \mathrm{mM}, \mathrm{MgCl} 2\right.$ $2.1 \mathrm{mM}$ ) before being maintained at $2.5^{\circ} \mathrm{C}$. Sperm quality was measured based on the sperm motility measured, and according to Yasui et al. $(2009,2012)$. Only samples that had progressive motility above $90 \%$ were used for the fertilization trials. Oocytes were collected by stripping on a plastic Petri dish $(100 \mathrm{~mm}$ diameter) covered with a plastic film (Saran wrap, Alpfilm, São Paulo, Brazil). The oocytes were then immersed in calcium and magnesium-free Dulbecco's phosphate-buffered saline (dPBS) (Sigma \#D5773), enriched with $0.5 \%$ bovine serum albumin (BSA) and maintained in an incubator with oxygen demand and temperature set at $26^{\circ} \mathrm{C}$. A small aliquot containing $\sim 80$ oocytes was taken just after stripping by pipetting using a 1000- $\mu 1$ micropipette (Eppendorf, Germany) with a cut tip (open diameter $\sim 3 \mathrm{~mm}$ ). This aliquot was used immediately for insemination with $100 \mu \mathrm{l}$ of diluted sperm and then gamete activation was achieved by adding $5 \mathrm{ml}$ of distilled water. After 2 min post fertilization (mpf), the period in which the sperm motility stops (Pereira-Santos et al., 2016), water volume was increased to $50 \mathrm{ml}$ and then maintained for incubation at $26^{\circ} \mathrm{C}$. After $60,120,180$ or $240 \mathrm{~min}$ of storage in dPBS, aliquots were also fertilized as mentioned above.

\section{Analysis of the structure of the oocyte and embryo development}

The oocytes maintained in dPBS were photomicrographed with a stereomicroscope Nikon SMZ 1500 (Nikon, Tokyo, Japan). All treatments had their embryogenesis described and analyzed during the 2-cell, blastula, gastrula, segmentation, and hatching stages. After hatching, the larvae were classified as normal or abnormal based on their morphology according to the criteria described by Pereira-Santos et al. (2016) for A. altiparanae species. Embryogenesis was described using a stereomicroscope Nikon SMZ 1500 (Nikon, Tokyo, Japan) coupled with a charge coupled device (CCD) camera (Nikon SMZ 1500, Nikon, Tokyo, Japan).

\section{Larvae in the laboratory system}

During the first feeding stage, the larvae were stored in circular 2-litre plastic containers with constant aeration and temperature set at $28^{\circ} \mathrm{C}$. The larvae were fed three times a day with Artemia salina nauplii. Once a day and before the last feeding, the containers were 
cleaned in order to remove debris (uneaten Artemia and faeces and a partial water change of $75 \%$ of the water volume at the same temperature). During this process, mortality rate was recorded. After yolk absorption (3 days after hatching), each batch of fry was distributed in circular transparent acrylic containers that were $150 \mathrm{~mm}$ in diameter with a water volume of 1 litre. Each container was placed in a biochemical oxygen demand (BOD) incubator with the temperature set at $26^{\circ} \mathrm{C}$ and $12 \mathrm{~h}$ of light per day. Water quality was maintained by water changes performed twice a day, $1 \mathrm{~h}$ after feeding. Feeding consisted of an association of Artemia sp. with plankton. Plankton were sampled from a $1000 \mathrm{~m}^{2}$ fertilized earthen pond using a closing plankton mesh ( $40 \mu \mathrm{m}$ diameter), and the samples were then passed through a $100-\mu \mathrm{m}$ nylon mesh in order to keep only small-sized organisms. This procedure resulted in predominantly rotifers and copepod nauplii forms.

The fish were later transferred to aquaria with a capacity of 50 litres, in which they remained receiving the same diet. The water was changed partially every 2 days, and the temperature was maintained at $28^{\circ} \mathrm{C}$.

\section{Flow cytometry}

A small piece of dorsal fin $\left(\sim 2 \mathrm{~mm}^{2}\right)$ was clipped from the fish and then placed in a $1.5 \mathrm{ml}$ macrotube containing $120 \mu \mathrm{l}$ of lysing solution. The samples were incubated at room temperature for $30 \mathrm{~min}$ with vortexing at 5-min intervals. Staining was achieved with the addition of $800 \mu 1$ of calcium-free Dulbecco's PBS (Sigma \#D5773) containing DAPI at $1 \mu \mathrm{g} \mathrm{ml}^{-1}$. The samples were then filtered through a $30-\mu \mathrm{m}$ mesh (Celltrics, Partec, Germany). Stained samples were then analyzed using a Partec CyFlow Plody Analyzer (Partec GmBH, Germany) with a specific filter set for DAPI excitation $(358 \mathrm{~nm})$. A commercial kit was used for aquaculture and plants (Partec CyStain DNA2-step, Partec GmBH, Germany).

Samples were collected from all survivors in each treatment: 50 animals from the control group, 18 from the treatment with $60 \mathrm{~min}$ of storage, 17 from the 120 min treatment, and 11 from the $180 \mathrm{~min}$ treatment (see Table 1). No analysis of the 240 min treatment was performed because there was no survival at this time point.

\section{Blood smears}

Blood smears were prepared using a drop of heparinized blood on a microscope slide, while samples of the same amount of animals were analyzed using flow cytometry. Analyses were performed 144 days post animal hatching. Slides were dried at room temperature for $6 \mathrm{~h}$ and then fixed in methanol for 3 s. After $30 \mathrm{~min}$ of drying, the slides were stained for

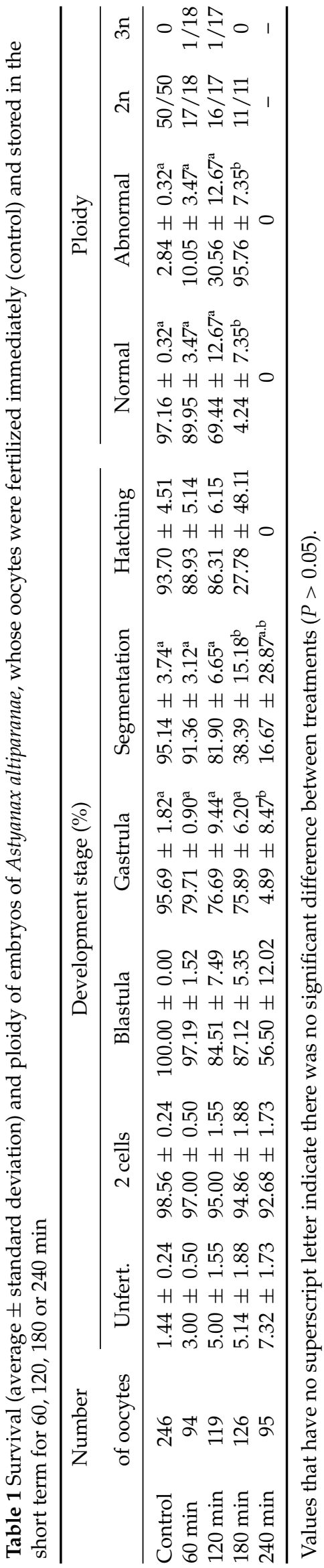


$10 \mathrm{~s}$ in a solution based on Giemsa (fast Panoptic kit supplied by Laborclin, Pinhais, Brazil). After staining, the slides were washed twice in Dulbecco's PBS (Sigma D5773), dried at room temperature, and then digital images of approximately 50 cells were taken using a trinocular microscope (Nikon Ci, Tokyo, Japan) with a CCD camera (Nikon DS-F1, Tokyo, Japan). The nuclear diameter was measured using the software elements - Ar NIS (Nikon, Tokyo, Japan).

\section{Statistics}

Data are presented as mean \pm standard error (SE). All experiments were performed with four replicates, using different sources of gametes. The data were checked for normality using the Liliefor test and, then, compared using analysis of variance (ANOVA) followed by Tukey's test $(P<0.05)$. Statistica 11 software was used for statistical analysis.

\section{Results}

\section{Analysis of the structure of the oocyte and embryo development}

After storage in Dulbecco's PBS solution for late fertilization, oocytes showed morphological patterns similar to those observed in fresh samples during the first hour of storage, including integrity of the yolk, dehydration, and chorium well adhered to the oocyte without the formation of the perivitelline (Fig. 1).

After $60 \mathrm{~min}$ of incubation, however, an increase in size of the perivitelline space was detected, which could also be related to an increase in the number of abnormal larvae at the subsequent hatching (Table 1). Such hydration during the storage time did not influence fertilization percentages between treatments, presenting no significant difference between these and the control group $(P=0.92)$.

Fertilization and survival rates during embryonic development of $A$. altiparanae using oocytes stored for 60, 120, 180, and $240 \mathrm{~min}$ are shown in Table 1. Embryonic development was described during each of the following phases: fertilization stage (zygote), 2-cell, blastula, gastrula, segmentation, and hatching.

From the early stages of development to the blastula stage, there was no statistical difference when compared with the control group (fertilized immediately following the extrusion) in all treatments $(P=0.99)$. All the morphological changes that compromised the viability and survival during embryogenesis were associated with the time during which oocytes were kept in an ex situ state until fertilized.

The control group embryos showed very satisfactory development (Fig. 2A-C), hatching percentages of
$93.70 \pm 4.51 \%$, and $97.16 \pm 0.32 \%$ of the percentage represented by normal larvae (Table 1).

Morphological analysis during early development differentiated a regular pattern of incidence observed between treatments. Embryos that resulted from oocytes stored for $60 \mathrm{~min}$ presented regular embryonic development until the early stages of blastula formation without major morphological changes in comparison with the control group (Fig. 2D-F). During the gastrula stage, however, alterations were observed throughout all stages of morphogenetic epiboly movements. The cells did not follow a regular pattern of division and had a reduced survival rate in the later stages. No significant differences were observed in the control group until hatching $(P=0.99)$.

The oocytes stored for 120 min resulted in embryos with an irregular pattern of development (Fig. 2GI). The gastrula and segmentation stages were the most affected during embryogenesis. The deformities observed during the gastrula stage covered the overall conformation of the embryo, showing an irregular aspect that often extends to the yolk region (Fig. $2 \mathrm{H}$ ). During the segmentation stage, the embryos presented abnormalities in the spine and in tail development during the pre-hatching period (Fig. 2I). Cephalic region development was normal, and the rise of optic and optical vesicles also developed normally. The percentage of abnormal larvae was $30.56 \pm 12.67 \%$. This finding suggests an atypical embryogenesis observed during the final stages of the segmentation stage, which was more evident at the pre-hatching stage. Swimming movements patterns for breaking the corium were affected as a result of bad tail formation.

After 180 min (Fig. 2J-L) of storage, embryos from fertilized oocytes presented pronounced deformities during the blastula, 2-cell, and hatching stages. During the blastula stage (512-1024 cells; Fig. 2J), an important stage for manipulation and cell transplantation, the cells presented an irregular division pattern, as there are cells of different diameters that can be associated with further irregular development and, therefore, decreased survival. The consequences of this pattern were more evident along the successive divisions when the embryos showed a significant decrease in survival embryos, as compared with other treatments $(38.39 \pm 15.18 \%)$. The main deformities observed within the resultant embryos were mainly an irregular development of the cephalic region. This is coupled with bad tail formation and column, with great variation in the number of somites between embryos that were in the same developmental stage, and standard irregular distribution of the yolk. In addition, a delay to reach each developmental stage was detected when compared with the control group that presented the most normal embryo development. The treatment 


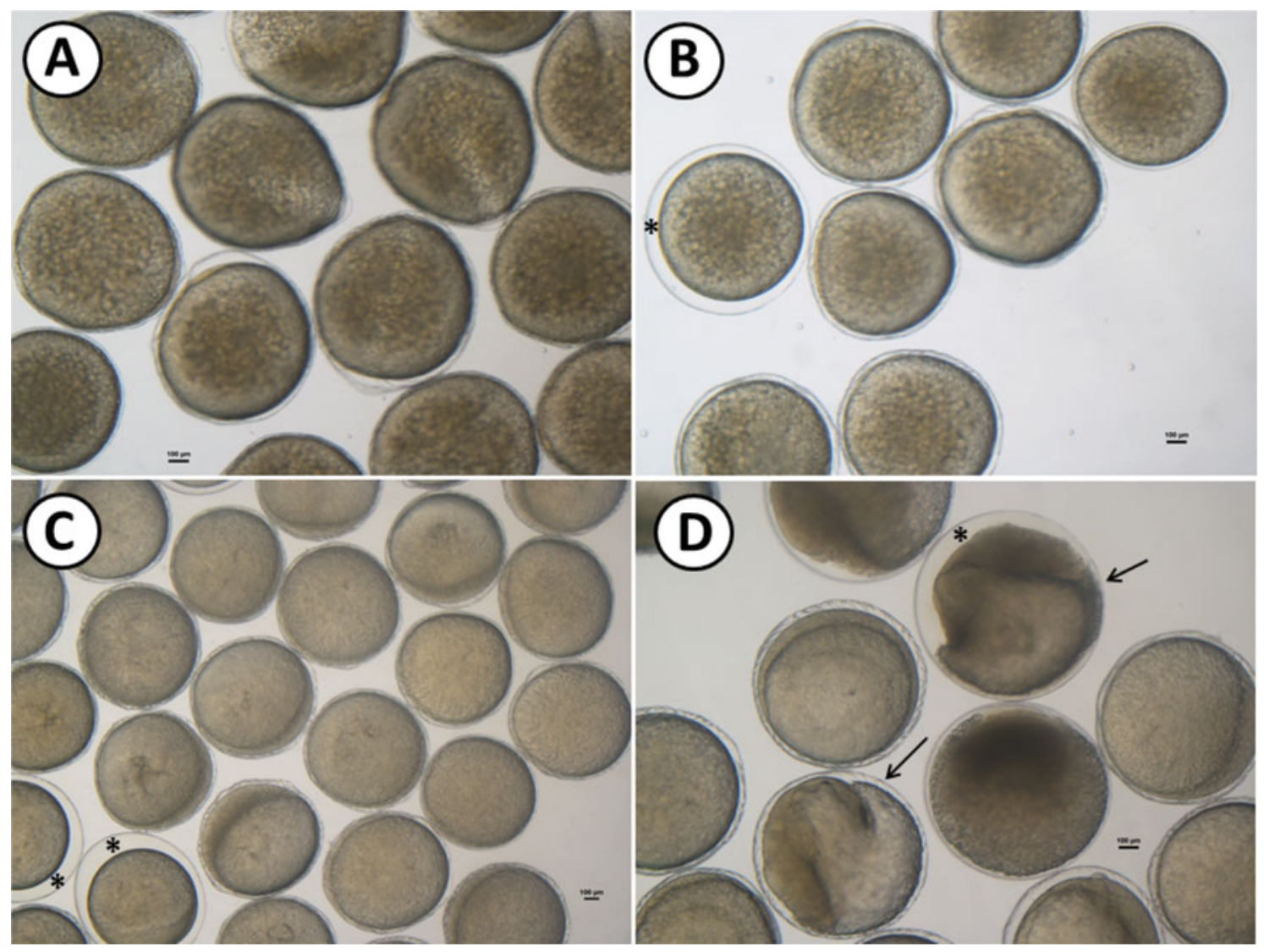

Figure 1 Oocytes of Astyanax altiparanae stored in the short term for $60 \mathrm{~min}(A), 120 \mathrm{~min}(B), 180 \mathrm{~min}(C)$, and $240 \mathrm{~min}(D)$. Asterisks indicate oocytes were partially or fully hydrated during storage; arrows highlight morphological changes in the structure of oocytes.

for $180 \mathrm{~min}$ gave the highest percentage of abnormal larvae $(95.76 \pm 7.35 \%, P=0.012)$.

Oocytes fertilized after $240 \mathrm{~min}$ of storage showed no survival after segmentation stage. Malformations were more intense during the gastrula stage (Fig. 2M-O). The yolk had an irregular conformation pattern, and the cell divisions were asynchronic, giving rise to an irregular epiboly movements that did not advance into later stages. During the gastrula stage, survival was decreased more than $50.00 \%$ in relation to the blastocyst stage $(4.89 \pm 8.47 \%)$. During the segmentation stage, there was survival for this $240 \mathrm{~min}$ treatment, but deformities were similar to those described for this stage in previous treatments, including malformations that decreased the viability of the embryos until hatching. The yolk presented an irregular shape, and the cephalic region did not develop synchronously. The tail had a high degree of deformity, representing embryos with lordosis and irregular pattern of somites distribution.

Given those morphologies and survival rates during the early stages, it was concluded that the oocyte storage time until fertilization affected the subsequent viability of the progeny, directly influencing their morphology and hence their survival.

\section{Larval stage}

In the control group, $97.16 \pm 0.32 \%$ of hatched larvae were normal, and only $2.84 \pm 0.32 \%$ were abnormal (Table 1 and Fig. $3 A$ ). For the percentage of normal larvae hatching, there was no significant difference between treatments for $60 \mathrm{~min}(P=0.90)$ and $120 \mathrm{~min}$ $(P=0.14)$ of storage after extrusion. There was no statistical difference in the treatment for $180 \mathrm{~min}$, in which the percentage of normal larvae fell to $4.24 \%(P=$ $0.05)$. Among the malformations observed throughout embryogenesis in storage treatments during embryogenesis, bad tail formations with an abnormal pattern of somites and loss of distribution that caused difficulty in swimming and subsequent mortality were observed. Among the hatched larvae from the $60 \mathrm{~min}$ storage of oocytes treatment, it was possible to highlight minor malformations in the tail differentiation region (Fig. 3B). The regions of the head and yolk followed normal patterns of development for the species. 


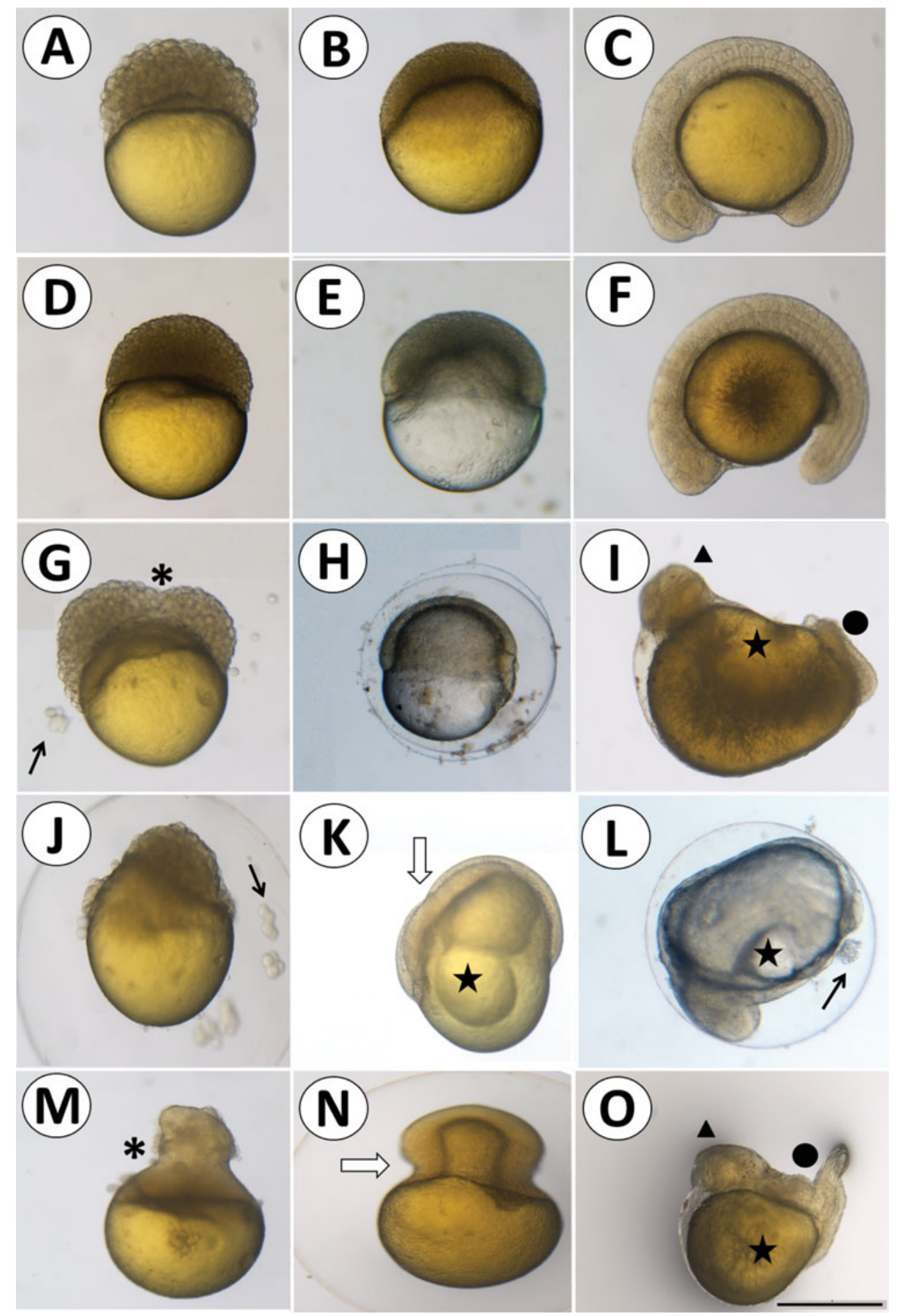

Figure 2 Morphological alterations along the embryonic development of Astyanax altiparanae embryos. Oocytes fertilized immediately after extrusion (control) showed no malformations in the blastula $(A)$, gastrula $(B)$, and segmentation $(C)$ stages. Then, oocytes whose embryos were fertilized after $60 \mathrm{~min}$ of extrusion in the blastula $(D)$, gastrula $(E)$, and segmentation $(F)$ stages; after $120 \mathrm{~min}$ of extrusion in blastula $(G)$, gastrula $(H)$, and segmentation (I) stages; after 180 min of extrusion in blastula $(J)$, gastrula $(K)$, and segmentation $(L)$ stages; and after $240 \mathrm{~min}$ of extrusion in blastula $(M)$, gastrula $(N)$, and segmentation $(O)$ stages. Asterisks indicate malformations during cell divisions of the blastoderm; arrows indicate detached cells from embryos during embryogenesis; white arrows indicate malformations during gastrulation; stars indicate malformations in shaping the yolk; triangles indicate malformations in the head; and circles represent malformations in the caudal region. Scale bar: $100 \mu \mathrm{m}$. 


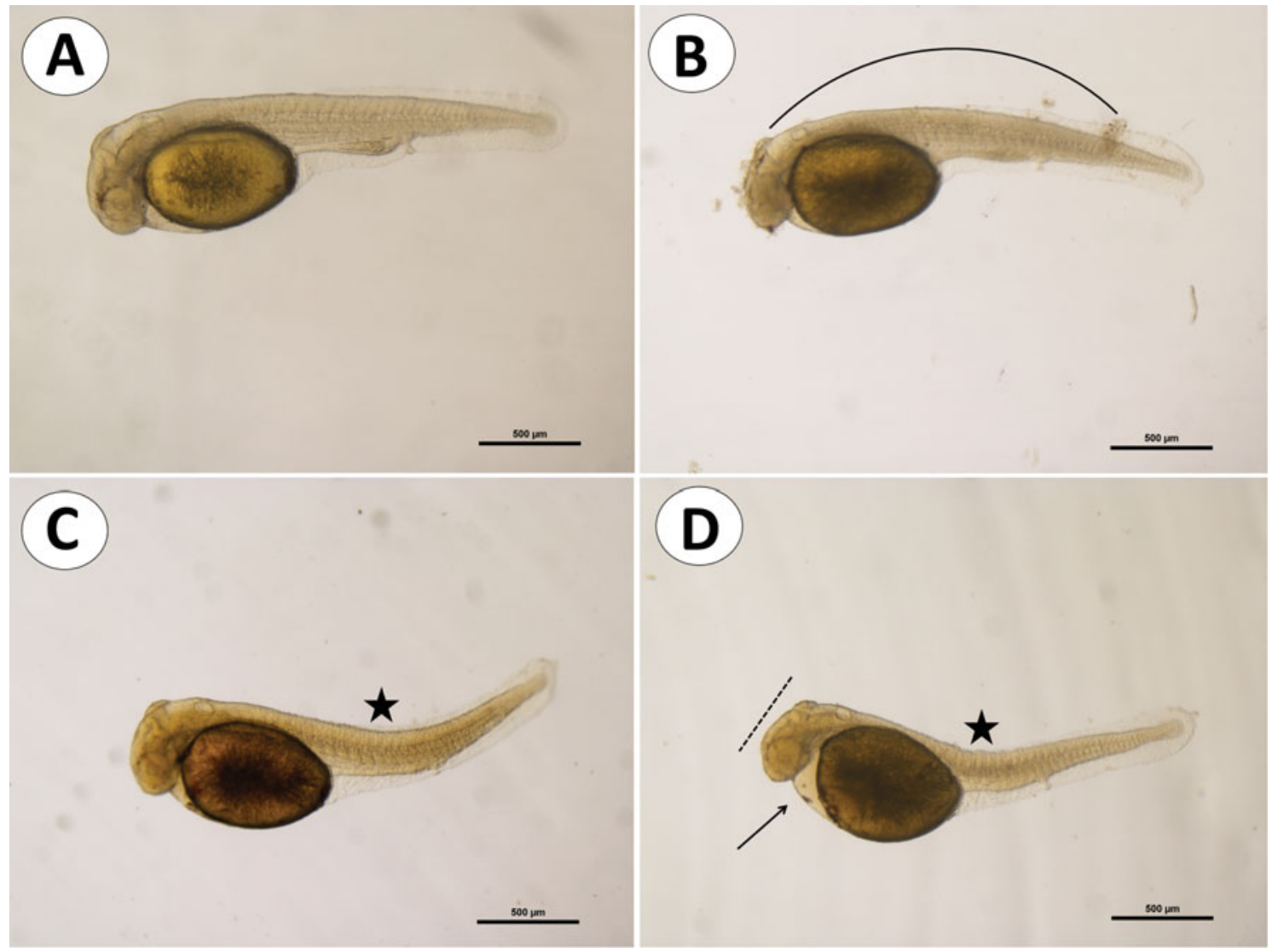

Figure 3 Larvae of Astyanax altiparanae from fertilized oocytes immediately after extrusion (control) $(A)$; fertilized after 60 min of storage $(B)$; after $120 \mathrm{~min}$ storage $(C)$; and after $180 \mathrm{~min}$ of storage $(D)$. Curved lines indicate abnormal development of the caudal region; stars indicate abnormal curvature of the tail, dashed lines indicate abnormal pattern of cephalic differentiation; and arrows indicate the unusual conformation of the yolk.

For the 120 min of storage of oocytes for fertilization treatment, the larvae hatched with malformations in the tail region, compromising their swimming movements and, consequently, the release of the corium (Fig. 3C). Some larvae also had deformities in the head and irregular patterns of distribution of the yolk. The hatched larvae with $180 \mathrm{~min}$ of storage of oocytes had serious tail and head deformities and differentiation of primitive gut and yolk distribution, manifesting in lower survival rate (Fig. 3D). Development was more lethargic and resulted in difficulty in larvae hatching because of the malformations. In the treatment using oocyte storage for $240 \mathrm{~min}$, there was no hatching and therefore no survival.

\section{Analysis of ploidy}

In the control group, $100 \%$ of the samples were diploid (Table 1). For treatment for $60 \mathrm{~min}, 95.56 \pm 4.44 \%$ $(17 / 18)$ of the samples were diploid, and $4.44 \pm 4.44 \%$ $(1 / 18)$ were triploid. After $120 \mathrm{~min}, 94.44 \pm 9.62 \%$ $(16 / 17)$ of the samples were diploid, and $5.56 \pm 5.56 \%$
$(1 / 17)$ were triploid; $100 \%$ of the samples were diploid after $180 \mathrm{~min}$ and $240 \mathrm{~min}$, resulting in no survival (Fig. 4).

\section{Discussion}

This study provides important information regarding oocyte sampling and subsequent fertilization for in vitro fertilization procedures. The storage time of oocytes after sampling may have an influence on embryo morphology, their viability and their survival, in addition to directly affecting ploidy of the resultant embryos.

According to Brooks et al. (1997), oocyte qualities are determined by the intrinsic properties of the egg itself and the environment in which the oocyte is fertilized and subsequently incubated. Most previous studies have focused on the fertilization ability of the oocytes after sampling, including a previous protocol from this laboratory for the same species (Yasui et al., 2014). In this study, the authors concluded that oocytes of this species may be stored for only for 


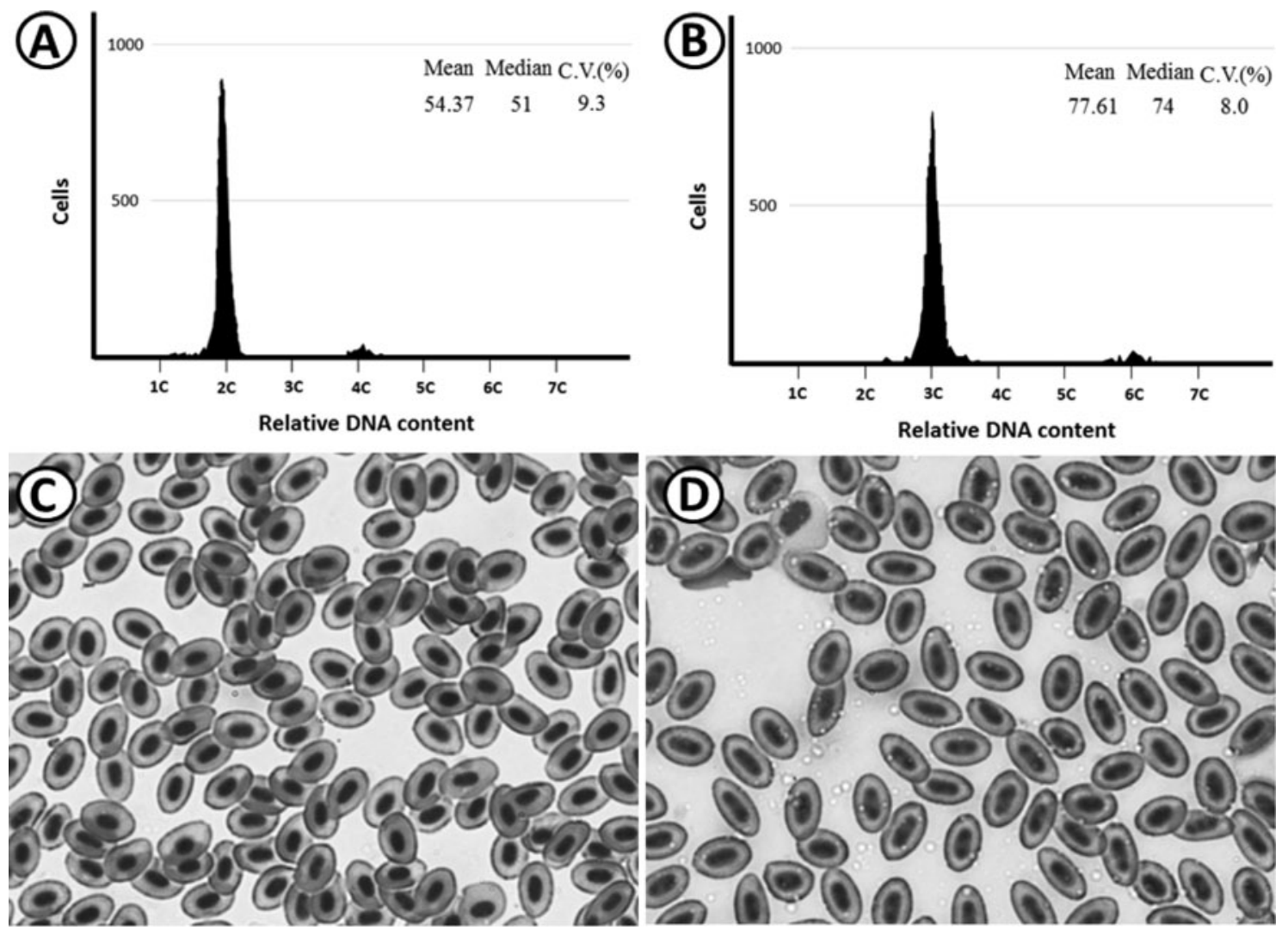

Figure 4 Ploidy analysis highlighting diploid and triploid individuals in the Astyanax altiparanae species, using flow cytometry $(A, B)$ and blood smears $(C, D)$.

few hours after sampling. Thus, it seems that oocyte viability is determined not only by external features including morphology, colour, and other aspects but by other factors that are important for the survival and maintenance of embryogenesis and, hence, the process of fertilization.

In general, oocyte quality can be defined as the ability to be fertilized and subsequently develop from an embryo to the adult stage in a normal way for the species. However, the presented data suggest that not only morphology may be affected after ovulation but also that the ploidy status can change. In fish, the occurrence of polyploids may give rise to sterile or infertile fish. In aquaculture, the quality of these gametes is very variable and is presented under the influence of a significant number of external factors. Moreover, other aspects related to the management and gene modulators related to the quality of gametes, which are little known, may affect the process (Bobe \& Labbé, 2010).

In this study, the fertilization rate of oocytes in A. altiparanae was satisfactory at $98.56 \pm 0.42 \%$ at an incubation temperature of $26^{\circ} \mathrm{C}$. This result demonstrates reproductive success of the species, even in oocyte storage conditions, in which there was little variation in percentage fertilization during treatment.
The effects of oocyte storage were more important and evident throughout embryogenesis and hatching. Such aspects emphasize that the fertilization rate does not determine an adequate development until the subsequent hatching stage.

The gradual loss of viability is constant between the teleost after ovulation (Rizzo et al., 2003), which can be directly related to the decrease of survival over embryonic development observed in this study. Prochilodus marggravii oocytes stored ex situ have lower fertilization rates quickly after ovulation and an increase in the percentage of deformed larvae. The same authors concluded that the storage period should not exceed $1 \mathrm{~h}$ under controlled temperature at $26^{\circ} \mathrm{C}$. Under similar conditions of incubation, this study concluded similar results for A. altiparanae, whose increase in the percentage of abnormal larvae is evident after $1 \mathrm{~h}$ of incubation ex situ and decreases to zero after $240 \mathrm{~min}$ of storage. The authors also concluded that the physical structures of the oocytes were preserved for up to $2 \mathrm{~h}$ of storage, and the decrease in fertilization percentage may not be associated with micropylar channels, which remained open during this interval. The stored $A$. altiparanae oocytes also maintained regular external morphological structure over $2 \mathrm{~h}$ of incubation. 
Oocyte storage of A. altiparanae affected the ploidy status, as well as influenced viability, embryo quality and, consequently, progeny survival. Such aspects are important for the aquaculture and also for improvement of chromosome manipulation techniques and other biotechnological approaches. Indirect induction of polyploids due to oocyte ageing may affect the production and propagation of the species. Triploid individuals, may be sterile and affect the upper diploid somatic growth of the same species (Piferrer et al., 2009).

In applied biotechnology, it is common to use techniques for inducing polyploid individuals for various purposes, such as chromosome manipulation (Fujimoto et al., 2010), induction of triploid individuals through tetraploid (Zhao et al., 2012), gynogenetic production (Felip et al., 2001), and chimerism (Yasui et al., 2011). In the execution of these techniques, factors, such as the time until oocyte fertilization and until technique application starting, may influence the ploidy of these progenies, as evidenced by this study. This situation can undermine the effectiveness of the protocols and the interpretation of results. Therefore, this study suggests that some spontaneous polyploids may arise from aged oocytes and, then, unexpected data may arise in the fields of chromosome set manipulation and micromanipulation. For instance, some spontaneous triploids may arise in eggs without any treatment. Such spontaneous polyploids may cause problems and misinterpretation in experiments, such as triploidization and gynogenetic induction, because triploids or gynogenetic diploids may arise in control groups in which only diploids and haploids are expected (Thorgaard et al., 1992; Komen \& Thorgaard, 2007).

Ageing of oocytes may be a possible explanation for the incidence of spontaneous triploids in natural populations of Astyanax species, such as the Astyanax schubartii (Morelli et al. 1983), Astyanax sp. (Kantek et al. 2007, Fauaz et al. 1994), and A. scabripinnis (Maistro et al. 1994, Machado et al. 2012). Contrary to suggestions by Machado et al. (2012) for Astyanax scabripinnis and Silva et al. (2011) for Rhandia quelen, natural triploids do not occur specifically due to temperature differences in the rivers on spawning grounds. As noted by this study, this natural occurrence can be explained based on instalment of the genus Astyanax spawns, which causes short-term storage of mature oocytes, which are then released by the females and fertilized. The occurrence of natural triploid individuals, due to such storage and late fertilization factors, was also reported by Nomura et al. (2013) for Anguilla japonica.

In conclusion, $A$. altiparanae oocytes should be used immediately after fertilization in order to avoid a decrease in the fertilization rate, mortality during embryo development and, also, alteration in the ploidy status. These findings are the first reports for neotropical species and are important for the application of reproductive technologies and to elucidate the occurrence of natural polyploids.

\section{Acknowledgements}

The authors are grateful to the National Center for Research and Conservation of Aquatic Biodiversity Continental (CEPTA/ICMBio), for providing the entire physical structure, providing biological material and technical support required and the Capes, the research project funding in the form of $\mathrm{PhD}$ scholarship and FAPESP (2010/17429-1).

\section{References}

Adamov, N.S.M., Nascimento, N.F., Maciel, E.C.S., PereiraSantos, M., Senhorini, J.A., Calado, L.L. \& Yasui, G.S. (2016). Triploid induction in the yellowtail tetra, Astyanax altiparanae, using temperature shock: tools for conservation and aquaculture. J. World Aquacult. Soc.. https://doi.org/ 10.1111/jwas.12390.

Bertolini, R.M., Senhorini, J.A., Nascimento, N.F., PereiraSantos, M., Nakaghi, L.S.O., Peres, W.A.M., Silva, R.C. \& Yasui, G.S. (2017). First feeding of diploid and triploid yellowtail tetra Astyanax altiparanae: an initial stage for application in laboratory studies. Aquacult. Res. DOI:10.1111/are.13433.

Bobe, J. \& Labbé, C. (2010). Egg and sperm quality in fish. Gen. Comp. Endocrinol. 165, 535-48.

Brooks, S., Tyler, C.R. \& Sumpter, J.P. (1997). Egg quality in fish: what makes a good egg? Rev. Fish Biol. Fish. 7, 387416.

Fauaz, G., Vicente, V.E. \& Moreira, O. (1994). Natural triploidy and B-chromosomes in the neotropical fish genus Astyanax (Characidae). Revista Brasileira de Genética 17, 15763.

Felip, A., Zanuy, S., Carrillo, M. \& Piferrer, F. (2001). Induction of triploid and gynogenesis in teleost fish with emphasis on marine species. Genética 111, 175-95.

Fujimoto, T., Yasui, G.S., Hayakawa, M., Sakao, S., Yamaha, E. \& Arai, K. (2010). Reproductive capacity of neotetraploid loaches produced using diploid spermatozoa from a natural tetraploid male. Aquaculture (Amsterdam) 308, S133-9.

Kantek, D.L.Z., Noleto, R.B., Fenocchio, A.S. \& Cestari, M.M. (2007). Cytotaxonomy, heterochromatic polymorphism and natural triploidy of a species of Astyanax (Pisces, Characidae) endemic to the Iguaçu River Basin. Brazilian Archives Biol. Technol. 50, 67-74.

Komen, H. \& Thorgaard, G.H. (2007). Androgenesis, gynogenesis and the production of clones in fishes: a review. Aquaculture 269, 150-73.

Machado, S.N., Neto, M.F., Bakkali, M., Vicari, M.R., Artoni, R.F., Oliveira, C.D. \& Foresti, F. (2012). Natural triploidy and $\mathrm{B}$ chromosomes in Astyanax scabripinnis (Characiformes, Characidae): a new occurrence. Caryologia 65, 40-6. 
Maistro, E.L., Lúcia Dias, A., Foresti, F., Oliveira, C. \& Filho, O.M. (1994). Natural triploidy in Astyanax scabripinnis (Pisces, Characidae) and simultaneous occurrence of macro B-chromosomes. Caryologia 47(3-4), 233-9.

Morelli, S., Bertollo, L.A.C., Foresti, F., Moreira, F.O. \& De Almeida Toledo, F.S. (1983). Cytogenetic considerations on the genus Astyanax (Pisces, Characidae). I. Karyotypic variability. Caryologia 36, 235-44.

Nascimento, N.F., Pereira-Santos, M., Piva, L.H., Manzini, B., Fujimoto, T., Senhorini, J.A., Yasui, G.S. \& Nakaghi, L.S.O. (2017). Growth, fatty acid composition and reproductive parameters of diploid and triploid yellowtail tetra Astyanax altiparanae. Aquaculture 471, 163-71.

Nomura, K., Takeda, Y., Unuma, T., Morishima, K., Tanaka, H., Arai, K. \& Ohta, H. (2013). Post ovulatory oocyte aging induces spontaneous occurrence of polyploids and mosaics in artificial fertilization of Japanese eel, Anguilla japonica. Aquaculture 404-5, 15-21.

Otani, S., Iwai, T., Nakahata, S., Sakai, C. \& Yamashita, M. (2009). Artificial fertilization by intracytoplasmic sperm injection in a teleost fish, the Medaka (Oryzias latipes). Biol. Reprod. 80, 175-83.

Pereira-Santos, M., Yasui, G.S., Xavier, P.L.P., Adamov, N.S.M., Nascimento, N.F., Fujimoto, T., Senhorini, J.A. \& Nakaghi, L.S.O. (2016). Morphology of gametes, postfertilization events and the effect of temperature on the embryonic development of Astyanax altiparanae (Teleostei, Characidae). Zygote 24, 795-807.

Piferrer, F., Beaumont, A., Falguiere, J.C., Flajshans, M., Haffray, P. \& Colombo, L. (2009). Polyploid fish and shellfish: production, biology and applications to aquaculture for performance improvement and genetic containment. Aquaculture 293, 125-56.

Rizzo, E., Godinho, H.P. \& Sato, Y. (2003). Short-term storage of oocytes from the neotropical teleost fish Prochilodus marggravii. Theriogenology 60, 1059-70.

Silva, M., Matoso, D.A., Ludwig, A.M., Gomes, E., Almeida, M.C., Vicari, M.R. \& Artoni, R.F. (2011). Natural triploidy in Rhamdia quelen identified by cytogenetic monitoring in
Iguaçu basin, southern Brazil. Environ. Biol. Fishes 91, 3616.

Sun, Y.H., Chen, S.P., Wang, Y.P., Hu, W. \& Zhu, Z.Y. (2005). Cytoplasmic impact on cross-genus cloned fish derived from transgenic common carp (Cyprinus carpio) nuclei and goldfish (Carassius auratus) enucleated eggs. Biol. Reprod. 72, 510-5.

Tanaka, D., Takahashi, A. \& Ueno, K. (2009). Morphometric characteristics and reproductive capacity of nuclear transplants derived from embryonic cells of loach, Misgurnus anguillicaudatus. J. Exp. Zool. 311A, 11-9.

Thorgaard, G.H., Sheerer, P.D. \& Zhang, J. (1992). Integration of chromosome set manipulation and transgenic technologies for fishes. Mol. Mar. Biol. Biotechnol. 1, 251-6.

Yasui, G.S., Arias-Rodrigues, L., Fujimoto, T. \& Arai, K. (2009). A sperm cryopreservation protocol for the loach Misgurnus anguillicaudatus and its applicability for other related species. Anim. Reprod. Sci. 116, 335-45.

Yasui, G.S., Fujimoto, T., Sakao, S., Yamaha, E. \& Arai, K. (2011). Production of loach (Misgurnus anguillicaudatus) germ-line chimera using transplantation of primordial germ cells isolated from cryopreserved blastomeres. $J$. Anim. Sci. 89, 2380-8.

Yasui, G.S., Fujimoto, T., Arias-Rodriguez, 1., Takagi, Y. \& Arai, K. (2012). The effect of ions and cryoprotectants upon sperm motility and fertilization success in the loach Misgurnus anguillicaudatus. Aquaculture (Amsterdam) 344-9, 147-52.

Yasui, G.S., Senhorini, J.A., Shimoda, E., Pereira-Santos, M., Nakaghi, L.S.O., Fujimoto, T., Arias-Rodrigues, L. \& Silva, L.A. (2015). Improvement of gamete quality and its shortterm storage: an approach for biotechnology in laboratory fish. Animal 9, 464-70.

Zhao, Y., Psenicka, M., Fujimoto, T., Saito, T., Yasui, G.S., Yamaha, E. \& Arai, K. (2012). Motility, morphology, mitochondria and ATP content of diploid spermatozoa from sex-reversed clonal diploid and neo-tetraploid loach. J. Appl. Ichthyol. 28, 1006-12. 